http://dx.doi.org/10.1016/S0954-6111(05)80346-4

7. Global Strategy for the Diagnosis, Management and Prevention of COPD, Global Initiative for Chronic Obstructive Lung Disease (GOLD) 2011. Available from: http://www.goldcopd.org/.

8. Ferguson GT, Enright $\mathrm{P}$, Buist AS, Higgins MW. Office spirometry for lung health assessment in adults. A consensus statement from the National Lung Health Education Program. Chest 2000;117:1146-61. http://dx.doi.org/10.1378/chest.117.4.1146

9. Enright PL, Skloot GS, Cox-Ganser JM, Udasin IG, Herbert R. Quality of Spirometry Performed by 13,599 Participants in the World Trade Center Worker and Volunteer Medical Screening Program. Respir Care 2010;55(3):303-09.
10. Leuppi JD, Miedinger D, Chhajed PN, et al. Quality of spirometry in primary care for case finding of airway obstruction in smokers. Respiration 2010;79(6):469-74. Epub 2009/09/30.

11. Maio S, Sherrill DL, MacNee W, et al. The European Respiratory Society spirometry tent: a unique form of screening for airway obstruction. Eur Respir J 2012;39(6):1458-67. http://dx.doi.org/10.1183/09031936.00111910

(C) 2012 Primary Care Respiratory Society UK. All rights reserved. http://dx.doi.org/10.4104/pcrj.2012.00064

\section{Diagnostic pathways for interstitial lung diseases in primary care}

\section{Dear Sirs,}

Interstitial lung diseases (ILDS) are characterised by inflammation or fibrosis of the lung parenchyma. ${ }^{1}$ Because of their low incidence and non-specific symptoms, ILDs are difficult to recognise, and this may cause diagnostic delay. ${ }^{2}$ We were very interested to read the review by Gulati on the diagnosis of ILDs published in the PCRJ last year, ${ }^{3}$ in which he concluded that, "General practitioners can prevent diagnostic delays by recognising clinical clues, reviewing relevant exposures, and uncovering the presence of possible connective tissue disease, as well as ordering HRCT chest scans and pulmonary function tests if possible." However, the diagnostic pathway for ILDs in primary care has hardly been studied. We would therefore like to comment on our recent work on the clinical presentation of ILDs, general practitioners' (GPs') diagnostic considerations, and delays between the initial GP consultation and referral to a medical specialist.

Using two Dutch primary care research databases, ${ }^{4,5}$ we identified 32 ILD patients fulfilling our inclusion criteria (i.e. data available preceding the diagnosis and referral to a medical specialist who made the formal ILD diagnosis between 1995 and 2005). Twenty-three patients (75\%) had been diagnosed with sarcoidosis, others with idiopathic pulmonary fibrosis $(n=5)$, extrinsic allergic alveolitis $(n=2)$, pulmonary fibrosis in scleroderma $(n=1)$, and bronchiolitis obliterans organising pneumonia $(n=1)$. Slightly more men $(56 \%)$ than women were included and the mean age at diagnosis was 48 years (range $22-80$ years).

During the first GP consultation two-thirds reported pulmonary symptoms and $44 \%$ reported systemic symptoms such as fatigue and fever (see Table 1). Nine patients presenting with joint pain or erythema nodosum were later diagnosed with sarcoidosis. Patients reported various other symptoms such as common cold symptoms, myalgia, gastro-intestinal complaints, nervous-functional complaints, visual disorders (in sarcoidosis), and Raynaud's syndrome (in scleroderma). In patients presenting with pulmonary symptoms, common initial working diagnoses were airway infections $(n=13)$, asthma/COPD $(n=5)$, and hyperventilation $(n=5)$. Interestingly, heart failure $(n=5)$ and pulmonary embolism $(n=4)$ was suspected in patients who presented with dyspnoea. Rheumatic fever and arthritis were common working diagnoses in patients presenting with joint pain $(n=5)$.

Before referral to a medical specialist, patients had a mean of four GP consultations (range 1-12). Mean time to referral was 13 weeks (range 0 days -19 months). Within four months, 75\% were referred and only three patients were referred after more than a year. Patients presenting with joint pain or erythema nodosum $(n=9)$ were referred relatively soon (mean time to referral 18 days versus 4 months in other patients). Eight of them were referred to a rheumatologist or internist. In
Table 1. Symptoms presented by patients diagnosed with interstitial lung disease $(n=32)$

\begin{tabular}{lll} 
Symptoms & $\begin{array}{l}\text { First Visit } \\
\text { N (\%) }\end{array}$ & $\begin{array}{l}\text { All Visits } \\
\text { N (\%) }\end{array}$ \\
\hline Pulmonary & $21(66 \%)$ & $22(69 \%)$ \\
\hline Dyspnoea & $12(38 \%)$ & $15(47 \%)$ \\
\hline Cough & $10(31 \%)$ & $12(31 \%)$ \\
\hline Thoracic pain & $4(13 \%)$ & $4(13 \%)$ \\
\hline Sputum & $3(9 \%)$ & $5(16 \%)$ \\
\hline Crepitations & $4(13 \%)$ & $9(28 \%)$ \\
\hline Prolonged expiration & $0(0 \%)$ & $1(3 \%)$ \\
\hline Wheezing & $0(0 \%)$ & $2(6 \%)$ \\
\hline Systemic & $14(44 \%)$ & $21(66 \%)$ \\
\hline Fatigue & $9(28 \%)$ & $15(47 \%)$ \\
\hline Fever & $3(9 \%)$ & $10(31 \%)$ \\
\hline Weight loss & $2(6 \%)$ & $4(13 \%)$ \\
\hline Night sweats & $0(0 \%)$ & $1(3 \%)$ \\
\hline Joint pain & $7(22 \%)$ & $7(22 \%)$ \\
\hline Erythema nodosum & $1(3 \%)$ & $4(12 \%)$ \\
\hline Other & $17(53 \%)$ & $20(63 \%)$ \\
\hline
\end{tabular}

contrast, almost all patients who presented with pulmonary or systemic symptoms were referred to a chest physician (83\%). Four ended up seeing an internist, ophthalmologist or cardiologist, which may have caused a significant diagnostic delay.

The diagnostic delay of ILDs in general practice should be seen in the light of the relatively common symptoms and signs with which most patients initially present - i.e. dyspnoea, cough, crepitations, thoracic pain, fatigue, fever. Understandably, more common diseases such as respiratory infections, asthma and COPD are considered first, and GPS rightfully choose "watchful waiting" because symptoms such as these are often self-limiting. This protects patients against undue, costly and potentially risky diagnostic tests, and may even reduce diagnostic delay caused by referral to the wrong specialist. As Gulati advises, ${ }^{3}$ if symptoms persist and advanced diagnostic services are available, a GP can then order a non-invasive HRCT scan to identify an ILD, and refer as appropriate. As most ILDs are very rare, a definitive diagnosis by a GP is not feasible and referral to the appropriate specialist is warranted. The role of general practice could be strengthened by specifying those clinical characteristics that make ILDs stand out from diseases like asthma or COPD on initial presentation and in the first weeks of follow-up, although we acknowledge that this may be difficult. 
*Marianne J Heins ${ }^{\mathrm{a}}$, Tjard RJ Schermer ${ }^{\mathrm{b}}$, Marleen EA de Saegher ${ }^{c}$, Kees van Boven ${ }^{b}$, Chris van Weel ${ }^{b}$, Jan C Grutters ${ }^{\mathrm{d}, e}$

a Radboud University Nijmegen, Expert centre for chronic fatigue, The Netherlands

b Radboud University Nijmegen Medical Centre, Department of Primary and Community Care, Nijmegen, The Netherlands

c Medisch Spectrum Twente, Department of Pulmonary Medicine, Enschede, The Netherlands

d St Antonius Hospital, Department of Pulmonology, Nieuwegein, The Netherlands

e University Medical Center Utrecht, Division Heart \& Lungs, Utrecht, The Netherlands

*Correspondence: m.heins@nkcv.umcn.nl

Received 17th July 2012; accepted 24th July 2012; online 30th August 2012

Acknowledgements We would like to thank Professor Wil van den Bosch and $\mathrm{Mr}$ Hans Bor for kindly providing data access and assisting with the CMR registry, and all participating primary care centres for their hospitality and assistance. In memory of Jules van den Bosch, who was the inspirator for this study.
Conflicts of interest The authors declare that they have no conflicts of interest in relation to this article.

Funding None.

\section{References}

1. American Thoracic Society/European Respiratory Society International Multidisciplinary Consensus Classification of the Idiopathic Interstitial Pneumonias. Am J Respir Crit Care Med 2002;165:277-304.

2. Judson MA, Thompson BW, Rabin DL, et al. The diagnostic pathway to sarcoidosis. Chest 2003;123:406-12. http://dx.doi.org/10.1378/chest.123.2.406

3. Gulati M. Diagnostic assessment of patients with interstitial lung disease. Prim Care Respir J 2011;20(2):120-7. http://dx.doi.org/10.4104/pcrj.2010.00079

4. Van Weel C. The continuous morbidity registration Nijmegen. Background and history of a Dutch General Practice Database. Eur J Gen Pract 2008;14 (Suppl 1):5A12.

5. Solera JK, Okkes I, Oskam S, et al., for the Transition Project. An international comparative family medicine study of the Transition Project data from the Netherlands, Malta and Serbia. Is family medicine an international discipline? Comparing incidence and prevalence rates of reasons for encounter and diagnostic titles of episodes of care across populations. Fam Pract 2012;29(3):283-98.

http://dx.doi.org/10.1093/f ampra/cmr098

(C) 2012 Primary Care Respiratory Society UK. All rights reserved.

http://dx.doi.org/10.4104/pcrj.2012.00074

\section{Available online at http://www.thepcrj.org}

